\title{
AN INVESTIGATION OF THE FRICTION AND WEAR PROPERTIES OF HIGH OLEIC VEGETABLE-BASED AND MINERAL OILS
}

\author{
Sanjeev K C a, Sushil Adhikari ${ }^{\text {b,c }}$ and Robert L. Jackson ${ }^{\text {a* }}$ \\ aDepartment of Mechanical Engineering, Auburn University, Auburn, 36849, USA \\ ${ }^{\mathrm{b} B i o s y s t e m s ~ E n g i n e e r i n g ~ D e p a r t m e n t, ~ A u b u r n ~ U n i v e r s i t y, ~ A u b u r n, ~ 36849, ~ U S A ~}$ \\ ${ }^{\mathrm{c}}$ Center for Bioenergy and Bioproducts, Auburn University, Auburn, 36849, USA \\ https://doi.org/10.35410/IJAEB.2021.5679
}

\begin{abstract}
This study investigates the wear and chemical properties of several vegetable-based oils based on different oleic content and compares them to a standard mineral base oil and inherent chemistries. A ball-on-disk tribometer test was performed to analyse the tribological properties of the oil under $50 \mathrm{~N}$ of applied load and at varying speeds. The functional groups of oils were tested using Fourier Transform Infrared Spectroscopy (FTIR) and viscosity was determined using a rheometer. Bio-derived oils had a lower coefficient of friction (COF) than the standard mineral base oil at different speeds. The presence of oleic acid in the vegetable oils helped to reduce the friction between the surfaces as compared to that of the mineral base oil. The presence of oleic content played a vital role during the wear analysis where high oleic content oil had lower wear compared to other bio- based oils and the standard mineral base. Abrasion was observed to be the dominant wear mechanism from the optical profilometer that included grooves on all the surfaces of the disk samples. The results showed that high oleic content oil has good potential to be an alternative to the standard mineral base oil.
\end{abstract}

Keywords: Friction; Wear; Tribometer; Profilometer

\section{INTRODUCTION}

The oil tanker "Prestige" sunk on September 13th, 2002, off the Galician coast which was one of the biggest spills in history and affecting several coastlines, ecological regions, aquatic species, and birds [1]. Mineral-based oils with additives/impurities are harmful to aquatic lives due to their toxic and non-biodegradable nature resulting in loss of several billions of dollars for cleanup purposes [2]. Similar incidents have resulted in huge public and governmental interests for alternatives to mineral-based oil. Bio-based oil is the best substitute for conventional mineralbased oil. Some forms of bio-based oil are also regarded as green energy from processes such as gasification, pyrolysis etc. [3][4]. The majority of the existing research is more focused on the development of bio-based fuels such as bio-diesel and blends of bio-oils that have a positive impact on the availability and environmental aspects [5][6]. Another major product of fossilbased oil is lubricants that prevent contact between asperities by forming a thin film or layer. Without adequate lubricants, the contact between two surfaces could lead to severe wear and eventually to catastrophic failure [7].

A lubricant acts as a protective layer for the longevity of the surfaces, transfers heat during operation, and reduces friction. A lubricant depends on the properties of the oil, and viscosity is a very important property that allows a bearing to operate in the hydrodynamic lubrication regime [8]. Viscosity is directly influenced by the intermolecular forces of the lubricant which at higher speed creates separation between surfaces and at low speed allows contact between surfaces. 
Therefore, lubricants are very important in everyday life and with an increase in environmental concern, research is conducted to use vegetable oils as base stocks for lubricants [9]. The boundary lubrication regime is a condition where there is solid contact between the surfaces and a formation of a low shear strength protective layer on the surface. In this condition, the reduction of friction is limited as compared to that of hydrodynamic lubrication due to the formation of the boundary layers on the contact asperities [10]. The boundary lubrication film formation occurs due to two mechanisms: physisorption and chemisorption. In physisorption, active molecules align normally on the contacting surface to form a protective layer. In chemisorption, active chemical groups react with the surface to form a tribo-surface and produce a boundary layer [11]. Vegetable oils are getting more attention as base oils than conventional mineral oils because of their biodegradability and renewability aspects. The interest in vegetablebased oil is due to the comparable chemical and physical properties of synthetic esters and mineral base oils. Ting and Chen [12] studied the viscosity and working efficiency of soybean oil, epoxidized soybean oil (ESO), and hydrogenated soybean oil for use as base oils. The results showed that the epoxidized soybean oil had higher viscosity compared to original soybean oil whereas hydrogenated has a lower viscosity. Castro et al. [13] studied the oxidation and wear properties of soybean oil, high-oleic soybean oil, and epoxidized soybean oil for base oil. Acceding to Castro et al. [13], high oleic soybean oil has good anti-wear properties due to lower polyunsaturated fatty acid content $(\sim 5 \%)$ as compared to soybean oil $(\sim 60 \%)$, forming a more stable polymeric film, whereas the presence of oxirane rings in ESO could reduce the binding properties resulting in more wear [13]. However, ESO showed a lower COF due to the formation of a tribochemical reaction on the surface as ESO could form polyester/polyether due to a tribopolymerization reaction.

Adhvaryu et al. [14] studied the tribological aspect of thermally and chemically modified soybean oils for environmentally friendly lubricants. The chemically modified soybean oil has greater wear protection than the thermally modified soybean oil, which was due to an increase in the polar functionality group in the chemically modified soybean oil. Adding functionality groups helped for stronger adsorption potential on the metal surface with greater lateral interaction between ester chains. Sharma et al. [15] explored the combination of antiwear and antioxidant additives to improve the oxidation behaviour properties of soybean oil. The results showed that the combination of zinc dialkyldithiocarbamate antioxidant and antimony dithiocarbamates showed good results for improving both the antiwear and antioxidant properties of soybean oil. Lal and Carrick [16] conducted performance-based testing of mineral oil with high oleic vegetable oil for thermal and oxidative stability, viscosity, and low-temperature properties. High oleic vegetable oil had comparable properties to that of the mineral base with the addition of additives to improve the oxidative and thermal properties of vegetable oil, however, a wear analysis was not reported in the study.

Minami and Mistsume [17] studied the effect of phosphorous on the antiwear properties of vegetable oil and mineral base oil under boundary lubrication conditions. Additives were put into the mineral base oil, to improve the antiwear properties of vegetable oil, and wear reduction was dependent on the peroxide value of the base oil. The peroxide formation was mainly due to the autooxidation mechanism of the vegetable oil that was observed at room temperature. 
Kraipat [18] studied the wear properties of different soybean oils using a four-ball wear tester and found that temperature, speed, and ZDDP additives have a significant effect on wear scar diameters. Wear scar diameter for epoxidized soybean oil and high oleic soybean oil was affected by the temperature, whereas for conventional soybean oil, the interaction between speed and additive played a significant role [18]. Adamczewska and Wilson [19] found less wear in a pump test for a combination of vegetable oil and additives to that of mineral oils. This test was particularly focused on lubricants for farm tractors.

Some research has been conducted to study the friction and antiwear properties of vegetablebased oil as compared to the mineral base oil, but more is needed. High oleic content in vegetable oil has good friction and wear properties. However, a comparative study of vegetablebased oil with different oleic content without any inherent chemistries to that of mineral oil with inherent chemistries would help to provide vital information for further research on vegetablebased lubricants. This paper focuses on the comparative study of vegetable-based oils (particularly high oleic content) and compares the friction and wear results with inherent chemistries on a mineral base. The chemical properties are analysed to determine the functional groups and their effect on friction and wear properties. The results will help to determine the potential of vegetable-based oil as an alternative to conventional mineral-based oil for lubrication.

\section{MATERIALS AND METHODS}

\subsection{Materials}

Four bio-based oils with different compositions, a mineral base oil, and gear oil additives were obtained from various industries which can be found in Appendix A. The disk samples were AISI 1018 steel with a surface roughness $(\mathrm{Ra})$ of 0.5 micrometres and were machined to size. The resulting disks were $7 \mathrm{~mm}$ thick with a diameter of $69.9 \mathrm{~mm}$ as shown in Figure 1. A typical gear oil concentrate was used as an additive. Balls of $10 \mathrm{~mm}$ high steel $(\mathrm{Cr} 25)$ were used to conduct the ball on disk experiments with a Rockwell C hardness between 60 and 67. Dual laser infrared thermal temperature sensors were used to measure the temperature of the oil samples. A $120 \mathrm{~V}$ 600W lamp was used to supply heat which was controlled by a PCM solid state temperature controller via a thermocouple. Viscosity was determined using a rheometer for the temperature range of $25-100^{\circ} \mathrm{C}$ using a sample size of $2 \mathrm{ml}$. The functional groups of bio-oils were investigated using Fourier Transform Infrared (FTIR) spectroscopy. The samples were analysed for 32 scans, between 4000 to $700 \mathrm{~cm}^{-1}$ at a resolution of $4 \mathrm{~cm}^{-1}$. 


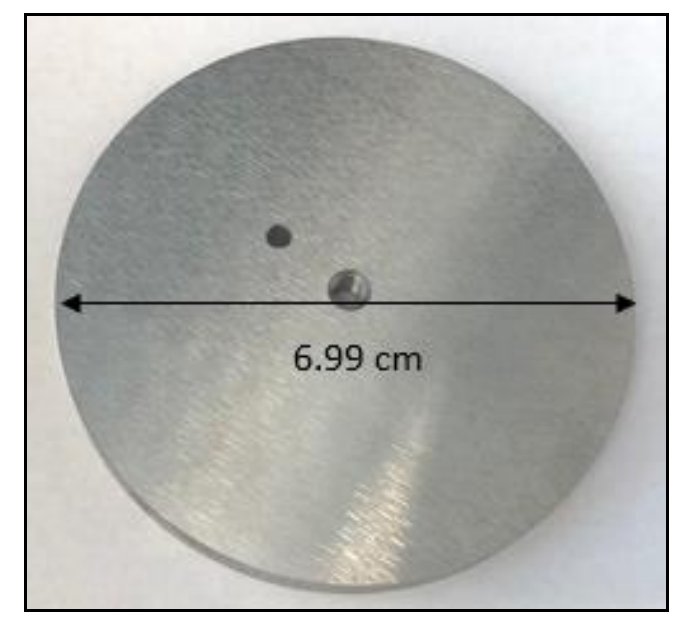

Figure 1: Picture of 1018 Steel disk sample

\subsection{Friction tests}

A ball-on disk friction and wear test was performed using a tribometer. Approximately $17 \mathrm{ml}$ of oil was poured on the holder to completely submerge the disk sample. The oil temperature was maintained at $90^{\circ} \mathrm{C}$ using a heating lamp and a temperature controller with a thermocouple placed above the holder. The temperature was constantly being monitored using a dual laser infrared thermal temperature sensor and thermocouple. A load of $50 \mathrm{~N}$ was applied to the ball against the disk at a radial distance of $16 \mathrm{~mm}$ from the centre. The total duration of the experiment was approximately 50 min which included applying the load, - at fourteen different speeds $(0.0016,0.00335,0.0084,0.0168,0.0335,0.084,0.134,0.167,0.251,0.335,0.42,0.502$, 0.586 , and 0.67$) \mathrm{m} / \mathrm{s}$ and removing the load. Figure 2 is the schematic of the experiment and Figure 3 is a sample disk after the experiment with a $\mathrm{Cr}$ steel ball. The balls and disks were cleaned using a sequence of acetone and methanol before and after the experiment to avoid surface contaminants. Each condition was performed in triplicate in a random order to lower the possibility of bias due to unknown external influences. The data obtained from the test includes $\mathrm{COF}$ and velocity in a tabular format. 


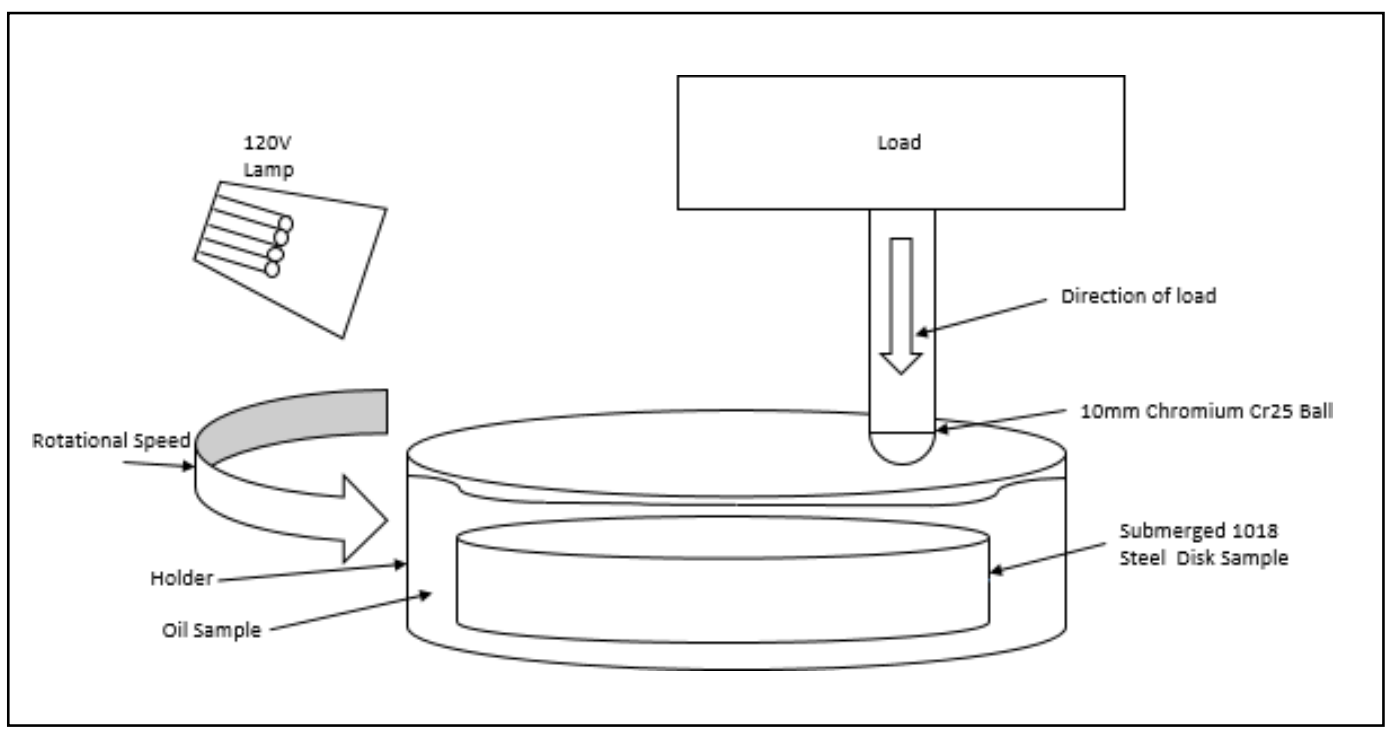

Figure 2: Schematic of a ball-on disk experiment

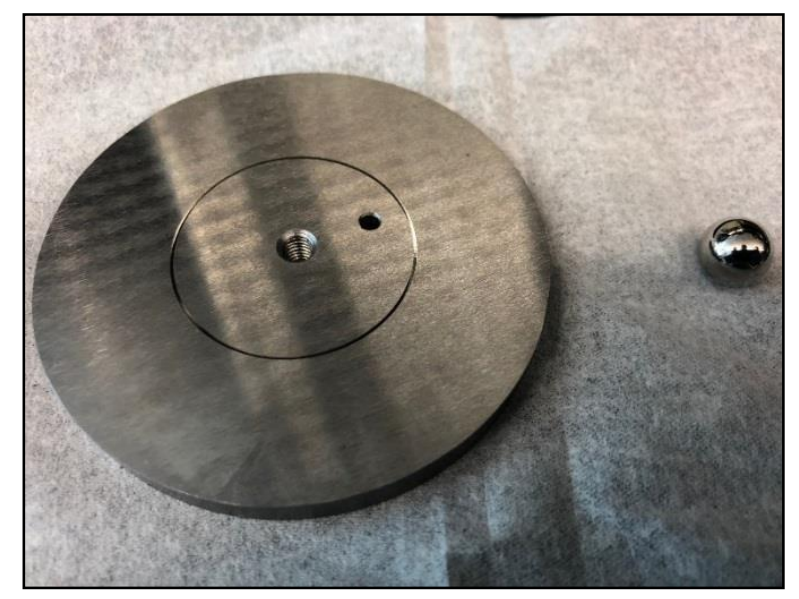

Figure 3: Sample disk and ball after test

\subsection{Wear analysis methodology}

Figure 4 represents the typical profile of the worn surface. A surface profilometer with a stylus of radius $12.5 \mu \mathrm{m}$, a force of $3 \mathrm{mg}$, was used to measure the profile of the worn surface. It was used to measure over a length of $8000 \mu \mathrm{m}$ with a lateral resolution of $1.5 \mu \mathrm{m}$, and a vertical resolution of approximately $1 \mathrm{~nm}$. The unworn portion of the profile was first extracted from the raw data to fit the linear line and was subsequently plotted on the worn surface to calculate the wear groove cross-sectional area. Each specimen was scanned three times at different angles, all 
perpendicular to the groove, to check the variation in the results. The average wear crosssectional area was calculated to evaluate the wear.

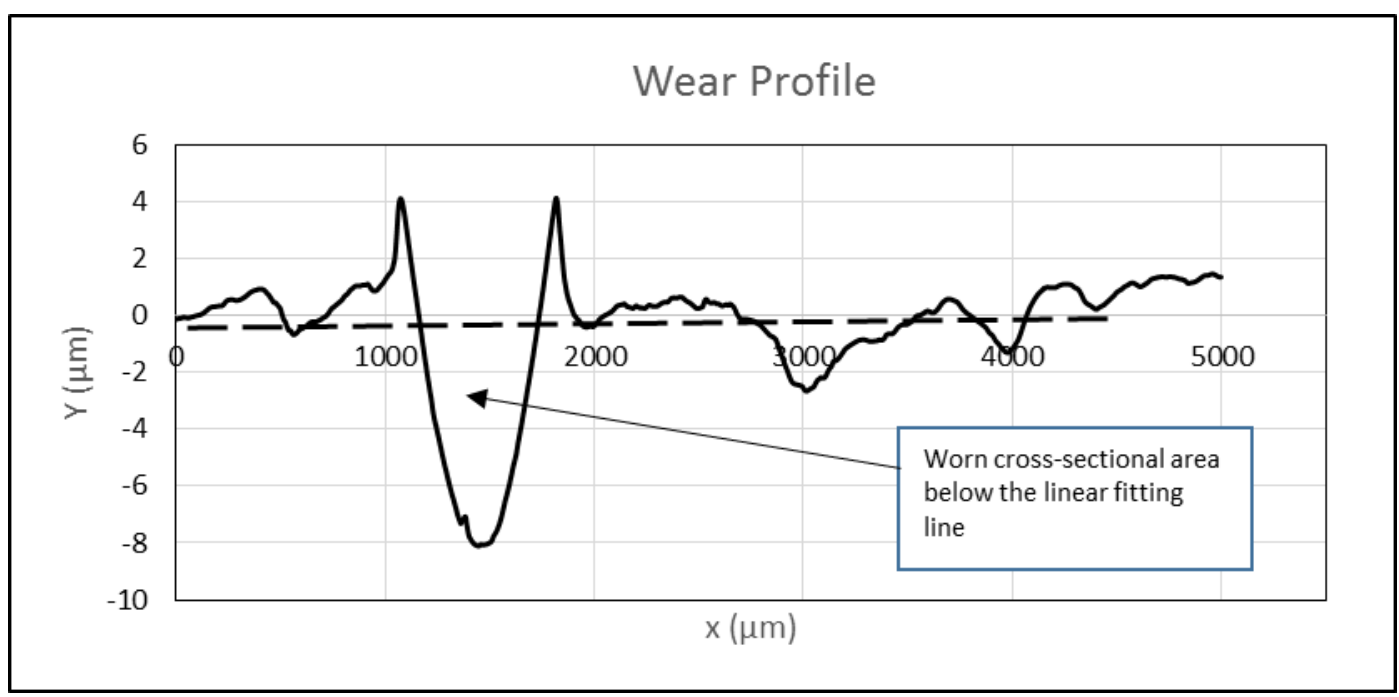

Figure 4: Typical profile of worn surface (Oil B $-50 \mathrm{~N}$ )

\section{RESULTS AND DISCUSSION}

\subsection{Effect of temperature on viscosity}

Figure 5 shows the effect of temperature on viscosity from room temperature of $25^{\circ} \mathrm{C}$ to $100^{\circ} \mathrm{C}$. ISO 68 has a high viscosity of around $0.16 \mathrm{~Pa} \cdot \mathrm{s}$ at room temperature but reduces to $0.036 \mathrm{~Pa} \cdot \mathrm{s}$ at $100^{\circ} \mathrm{C}$. Most of the trends show that the viscosity of oil reduces with an increase in temperature which is similar to the results obtained by Fasina et al. [20]. However, there is an increase in viscosity of oil A as the temperature is increased from $90^{\circ} \mathrm{C}$ to $100^{\circ} \mathrm{C}$ which may be due to a polymerization reaction. Oil $\mathrm{A}$ had a higher polymerization rate due to lower oleic content as compared to Oil C and Oil D. Ting and Chen [21] had a similar result for conventional soybean oil, however, their graph was limited to $80^{\circ} \mathrm{C}$. With an increase in temperature, volatile components in the vegetable oils also get vaporized which was observed in a study conducted by Castro et al. [13]. At a higher temperature of $175^{\circ} \mathrm{C}$ to $200^{\circ} \mathrm{C}$, higher molecular weight products were formed for conventional soybean oil which reduced the viscosity of the oil [13]. The volatile products (peroxides, alcohols, aldehydes, and other lower molecular weight compounds) formed during oxidation are vaporized due to a higher temperature and oxidation rate. 


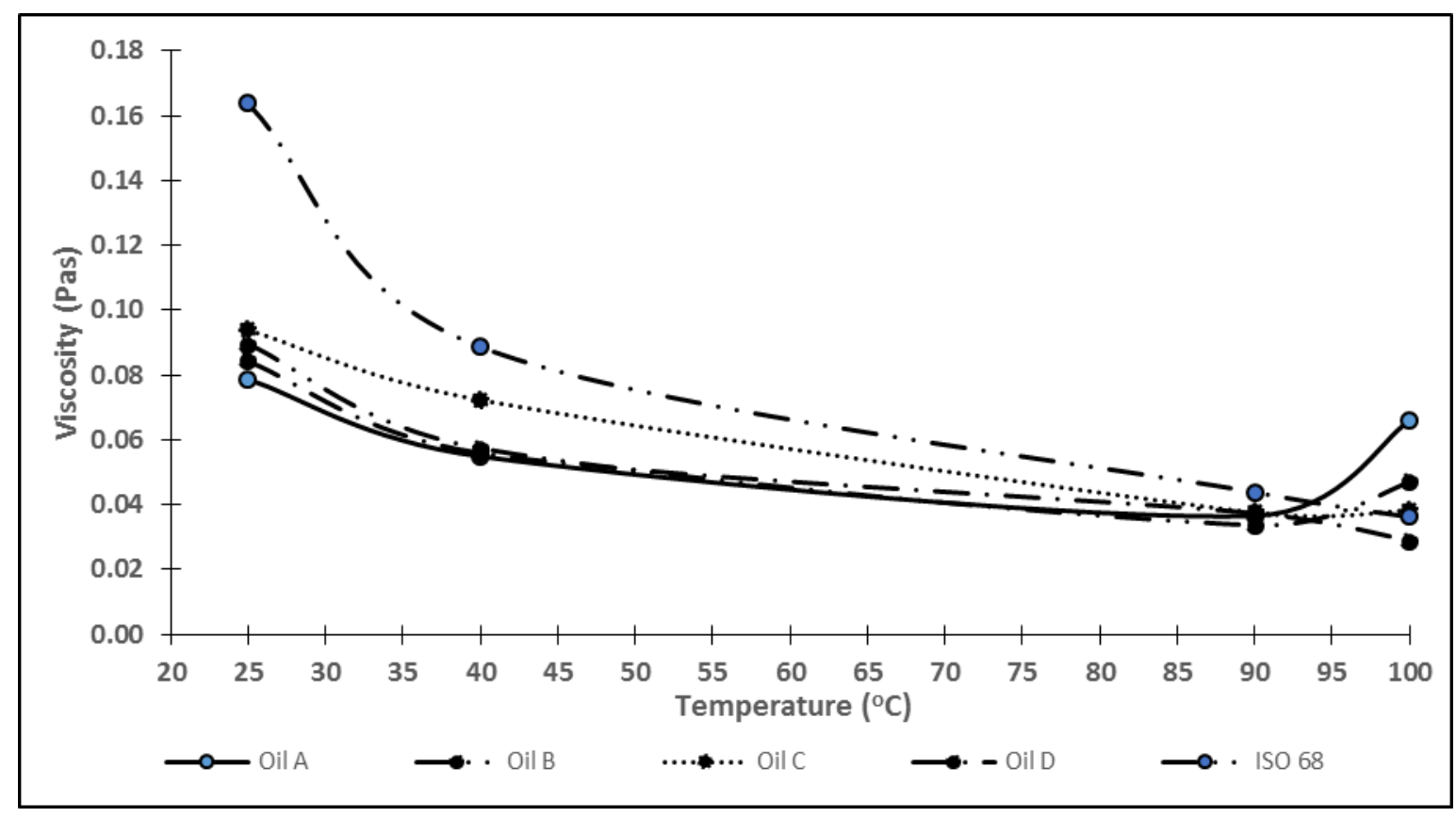

Figure 5: Measured viscosity as a function of temperature

\subsection{Analysis of wear}

Figure 6 shows the wear area analysis from the profilometer scans for all the experimental parameters after the conclusion of each test through all the speed ranges. At low speed, the metal surfaces are in contact resulting in higher wear. At a higher speed, a lubricating film is formed that could partially separate two surfaces. The fluid is pressurized at a higher speed to carry the applied load due to the elastohydrodynamic lift mechanism. However, according to established elastohydrodynamic models, the film is not theoretically enough to completely separate the surfaces (See Appendix A). Due to this and wear occurring during all of the tests the investigators believe that the tested contact is always in the boundary lubrication regime, and dominated by solid contact.

The effect of anti-wear additives is seen on ISO 68 base oil as the additives can form a coat of a protective layer on the metal surface by physisorption and adsorption mechanisms. The inclusion of additives at a higher percentage helps to reduce the wear that is observed in the boundary lubrication regime by creating a protective film between the surfaces. Wear rate is also influenced by the molecular structure of the oil that helps to determine either the physically or chemically adsorbed layers of the lubricants.

Polyunsaturated fatty acids (PUFA) are mostly found in vegetable oil and Oil A has a higher PUFA content $(\sim 60 \%)$ which is not ideal for lubrication [13]. The polyunsaturated fatty acid makes oil comparatively unstable due to oxidation agents (i.e. low oxidative stability). Therefore the lower the PUFA, the better the oxidative stability of the vegetable oils. Oxidation degradation 
of the oils will reduce their lubricating properties. Fox et al. [22] also observed that the increase in the level of unsaturation in the fatty acid has a negative influence in the boundary lubrication regime. High oleic soybean oil has better wear properties due to a stable polymeric film and lower PUFA content (5\%) compared to conventional soybean oil [13]. The wear result of Oil C was comparable to ISO 68 oil with a $0.25 \%$ conventional gear additive (add) concentration. Linoleic acid $\left(\mathrm{C}_{18: 2}\right)$ which is the predominant $\mathrm{n}-6$ polyunsaturated fatty acid (PUFA) is usually higher in Oil D and Oil B [23].

The reason for Oil D and Oil B to have higher wear could be because of a higher concentration of PUFA [13][23]. Note that the recommended concentration of gear oil additive is $0.25-10 \%$ depending on the nature of the work such as for worm gears $(3-10 \%)$ or spiral gears $(1 \%)$ [24][25].

This demonstrates how the high oleic oils with low PUFA have better inherent tribological properties than ISO 68 with some additives. This result suggests that high oleic bio-derived oils require fewer additives to reach the adequate performance achieved by mineral oils.

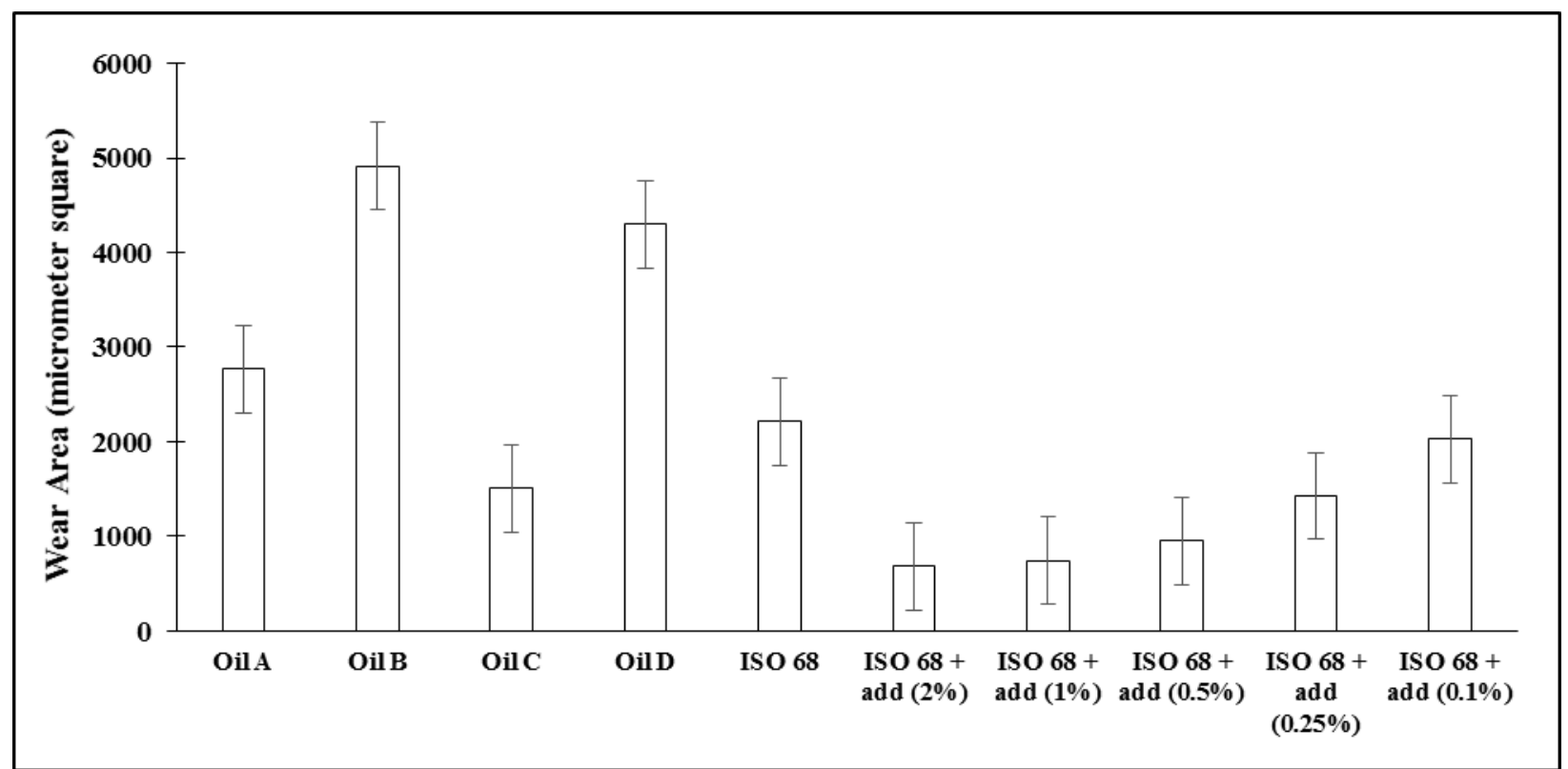

Figure 6: Wear area for all the experimental parameters

\subsection{Functional groups of oil}

The functional groups of the oil play a vital role in the friction and wear properties of the oil. Figure 7 (a) exhibits the Fourier-transform infrared spectroscopy (FTIR) of the oils without any additives. There are peaks across several wave number ranges $400-700 \mathrm{~cm}^{-1}$ as shown in Figure 7 (b), $1000-1700 \mathrm{~cm}^{-1}$ in Figure 7 (c), and $2800-3000 \mathrm{~cm}^{-1}$ in Figure 7 (d). Table 1 provides the 
functional group information based on wavenumber. The region between $400-700 \mathrm{~cm}^{-1}$ is very hard to interpret which is referred as the fingerprint region since there are many peaks and it is exceptionally difficult to interpret. The region from $1000 \mathrm{~cm}^{-1}$ and above can be interpreted and provides vital information about the functional groups of the oil. In the case of ISO 68 base oil, there were peaks between $2912-2930 \mathrm{~cm}^{-1}$ of C-H stretching that represent a strong long-chain alkane group. There were peaks in this range for each oil particularly between $2840-3000 \mathrm{~cm}^{-1}$ that represented the $\mathrm{C}-\mathrm{H}$ bond stretching in each oil. The peaks that were observed between $2695-2800 \mathrm{~cm}^{-1}$ for Oil D and Oil C were C-H stretching that represented aldehydes.

The peaks between $1700-1720 \mathrm{~cm}^{-1}$ represented $\mathrm{C}=\mathrm{O}$ stretching functional groups for acids and ketones. The $\mathrm{C}=\mathrm{O}$ is saturated and thus stable which helps to form a film layer during boundary lubrication which was also observed by Castro et al. [13]. The peaks at 1425 and $1437 \mathrm{~cm}^{-1}$ represented the O-H stretching groups that were present in Oil B and Oil A. The peaks near 1717 $\mathrm{cm}^{-1}$ represented $\mathrm{C}=\mathrm{O}$ stretching ketonic groups in both Oil B and Oil A that were observed by Adhvaryu et al. [2]. Oil C also included the presence of a sharp peak at $1447 \mathrm{~cm}^{-1}$ between 1457$1461 \mathrm{~cm}^{-1}$ represented $\mathrm{CH}_{3}$ stretching, and medium peaks between $1462-1467 \mathrm{~cm}^{-1}$ represented C- $\mathrm{H}$ stretching.

Table 1: Wavenumber and functional groups

\begin{tabular}{|l|l|}
\hline Wavenumber $\mathbf{c m}^{-1} \mathbf{)}$ & Functional Group \\
\hline $400-700$ & Fingerprint Region \\
\hline 1425 and 1437 & Hydroxyl \\
\hline $1457-1461$ & Alkyl group \\
\hline $1462-1467$ & C-H \\
\hline $1700-1720$ & Acids and Ketons \\
\hline $2695-2800$ & Aldehydes \\
\hline $2840-3000$ & C-H Bond \\
\hline $2912-2930$ & Long-Chain Alkane group \\
\hline
\end{tabular}


Vol. 06, No. 05; 2021

ISSN: $2456-8643$
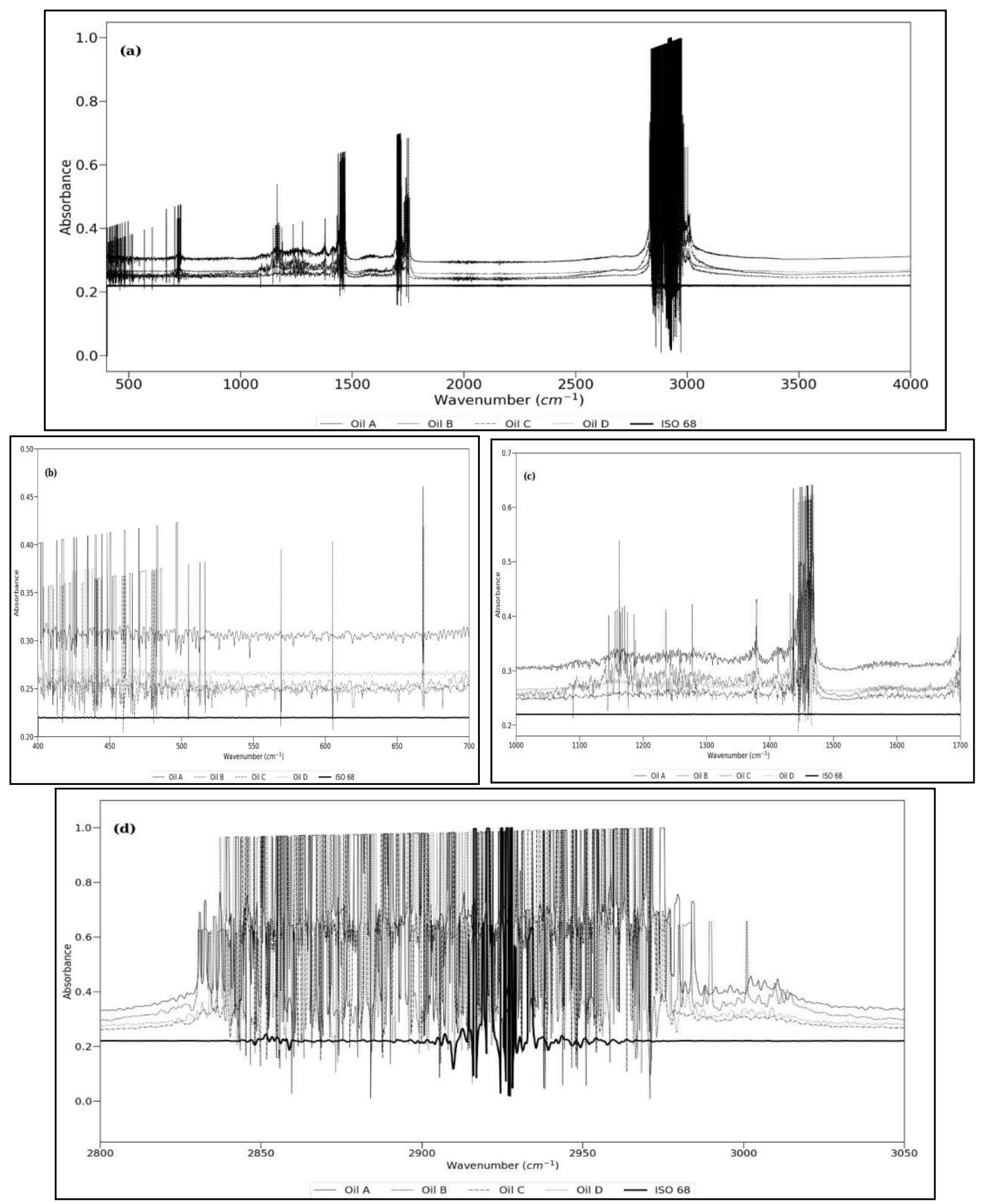

Figure 7: a) Overall view of FTI; b) FTIR for $400-700 \mathrm{~cm}^{-1}$; c) FTIR analysis for wavelength between $-1700 \mathrm{~cm}^{-1}$; and d) FTIR for wavelength between 2800 to $3500 \mathrm{~cm}^{-1}$ 
Vol. 06, No. 05; 2021

ISSN: $2456-8643$

\subsection{Stribeck curve}

The well-known Stribeck curve helps to describe the relationship between the COF, sliding speed, load, and viscosity in a lubricated contact [26]. The Hersey number is the dimensionless number obtained from the velocity $(\mathrm{m} / \mathrm{s})$ times the dynamic viscosity $(\mathrm{Pa} \cdot \mathrm{s}=\mathrm{N} \cdot \mathrm{s} / \mathrm{m} 2)$, divided by the load per unit length of bearing $(\mathrm{N} / \mathrm{m})$ which is defined in Appendix B. As shown in Figure 8, the results plotted using the Stribeck curve show the transition of the COF from low to high speed. Plotting the results in this way helps to account for the differences in viscosity between the lubricants. The COF of Oils A, B, C, and D are lower than the ISO 68 at lower speeds and continued in a similar pattern at higher speeds.

Elastohydrodynamic lubrication was used to calculate the minimum film thickness and $\lambda$ (ratio between the film thickness and surface roughness) using a model by Chittenden et al. [27]. Details about the calculation regarding $\lambda$ are present in Appendix C. The $\lambda$ for all the conditions were less than 0.1 that typically signifies boundary lubrication regime.

Vegetable oil contains polar functional groups (such as fatty acids) that are attracted to the metal surface and also due to reaction with the surface mainly by the presence of oxygen [28]. The effect of additives on ISO 68 could be seen in Figure 8 at higher speeds. The COF of ISO 68 at high speed was 0.126, which was reduced with the inclusion of additives. Reyes and Neville [29] observed similar results when base oils were added with ZDDP, ZDDP plus the addition of Casulphonate detergent, and MoDTP (Molybdenum Dithiophosphate). This reduction in COF indicates the effect of additives in the ISO 68. However, the additives never reduced the friction of the ISO 68 mineral oil to the friction range of the considered bio-oils, which suggests that they have inherently superior friction performance properties. 


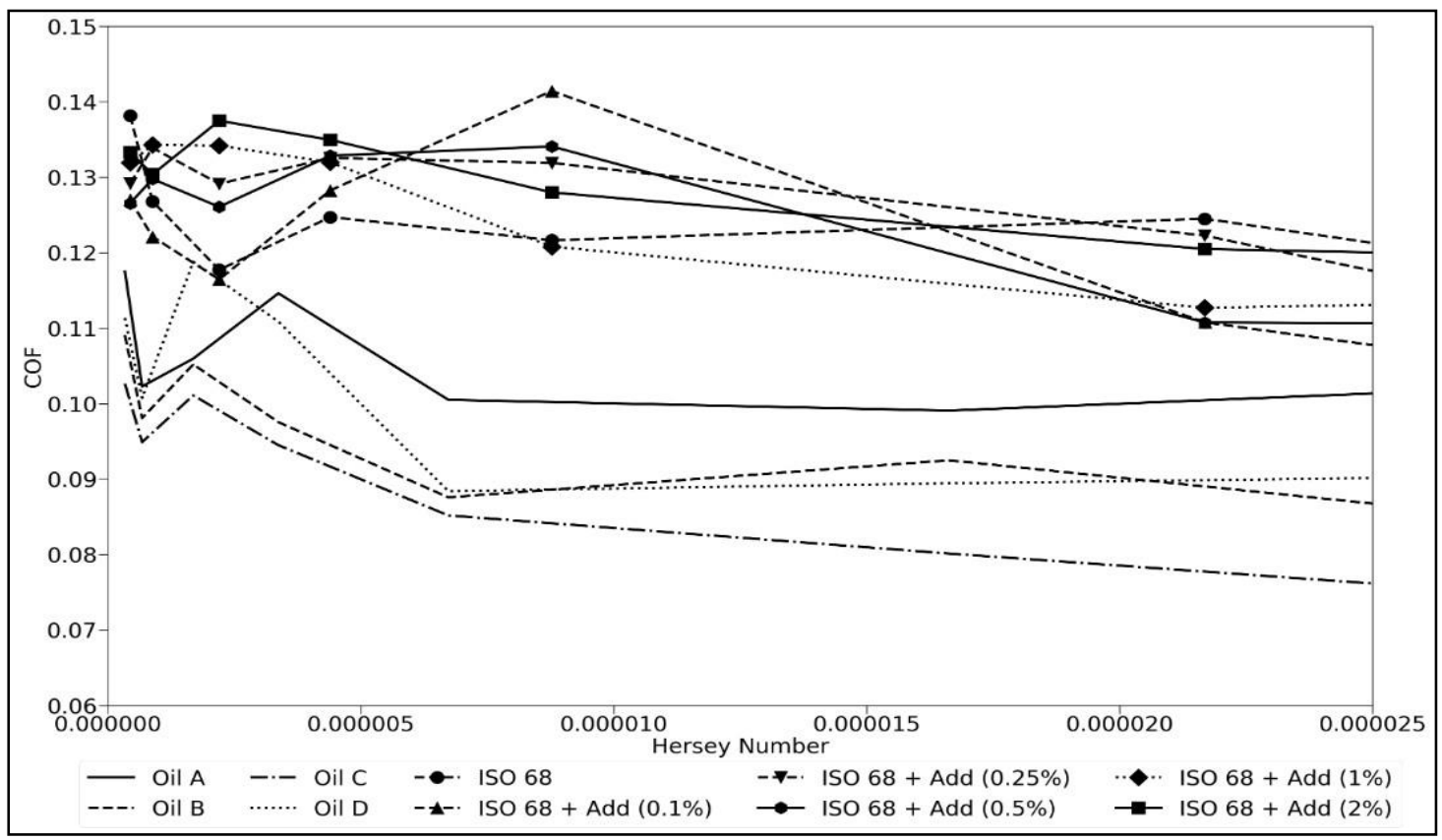

Figure 8: Stribeck Curve of the oil

\subsection{Optical image of the surface}

Optical images of the worn surfaces shown in Figure 9 help to diagnose the wear mechanism under different lubricating conditions during the ball on disk tests. The plowing line in Fig. 9 (a, $\mathrm{b}, \mathrm{c}$, and d) indicates the abrasive wear mechanism whereas the smearing surface indicates an adhesive wear mechanism. The dominant mechanism for wear in all the cases appears to be due to abrasive wear with some adhesion, which is similar for lubricated conditions as observed in a previous study [7]. The wear surface is mainly due to two-body abrasion where surface asperities are directly in contact with the boundary lubrication regime. The difference in hardness number between the ball and surface allowed the formation of abrasive grooves on the surface as observed in the images. The wear mechanism could have expanded from two-body to three-body abrasion as the debris could have squeezed in between the ball and disk surface. The presence of smearing wear could be because of some adhesive wear still occurring. The volatile fraction of the Oil $\mathrm{C}$ and Oil D might have evaporated at around $90^{\circ} \mathrm{C}$, resulting in a decrease in the lubricant film thickness, causing the surfaces to come closer together. Castro et al. [13] observed a higher evaporation rate of high oleic soybean oil when the temperature was elevated due to the formation of volatile products that occurred via scission alpha to the hydroperoxide group. Film thickness is directly related to wear surface types which were also observed by Shahabuddin et al. [30]. Wear would have also been influenced by the protective tribo-films of fatty acids formed from the high oleic bio-oils. ISO 68 is more resistant to temperature so asperity contact causes the wear to mainly be by abrasion. 
International Journal of Agriculture, Environment and Bioresearch

Vol. 06, No. 05; 2021

ISSN: $2456-8643$
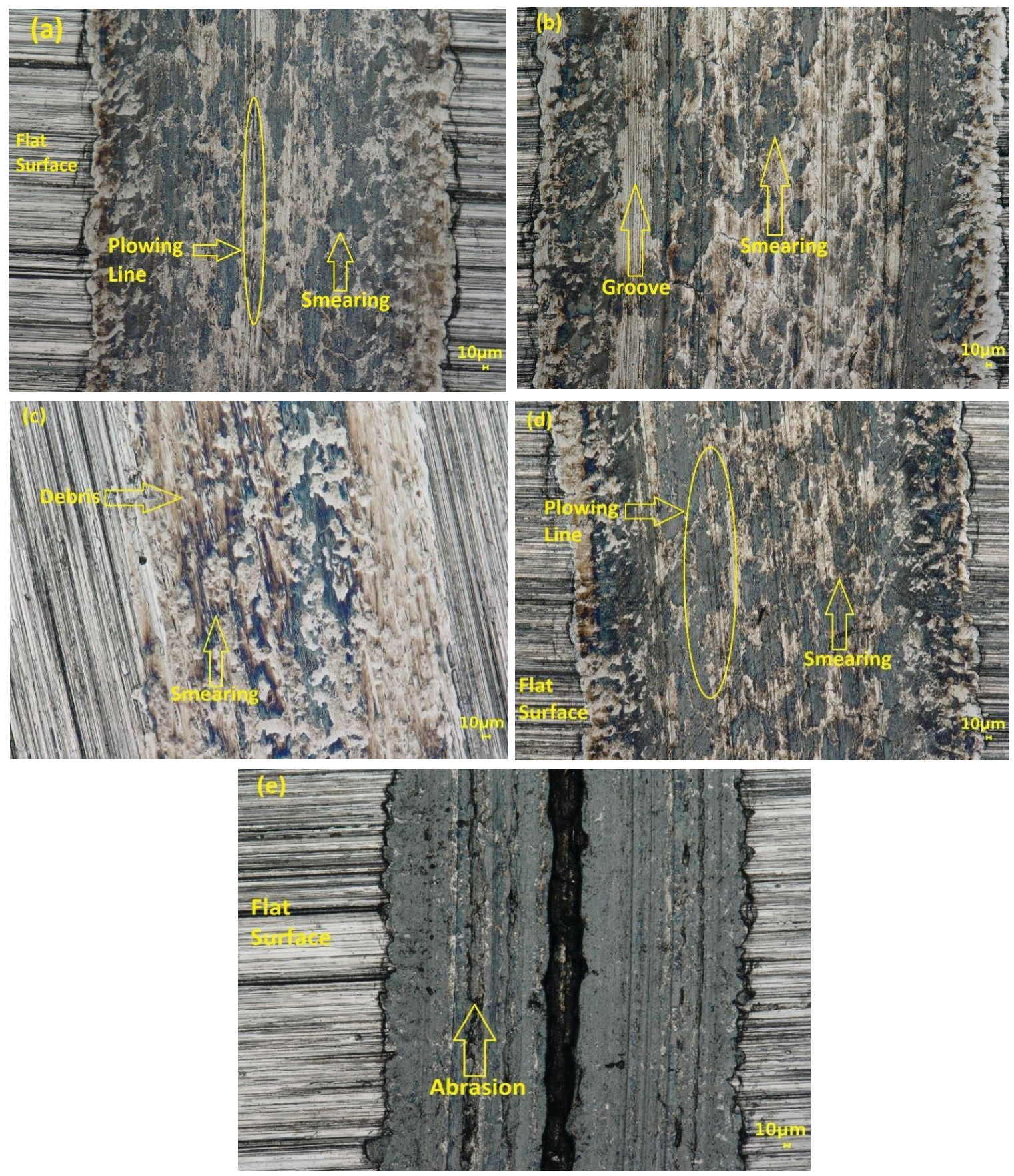

Figure 9: Surface profile from Optical Microscope: (a) Oil A, (b) Oil B, (c) Oil C, (d) Oil D, and (e) ISO 68 
Vol. 06, No. 05; 2021

ISSN: $2456-8643$

\section{CONCLUSION}

This study investigated the preliminary aspect of using vegetable oils without any additives as an alternative to the conventional mineral base oil with and without additives. The results obtained from the chemical and tribometer tests were used to evaluate the friction and wear properties of the oil. The following conclusions can be drawn based on the experimental results and observations:

1. The viscosity properties of the various bio-derived oils were comparable to the standard base oil at a temperature of around $90^{\circ} \mathrm{C}$. Oil A viscosity increased as the temperature at around $100^{\circ} \mathrm{C}$ that could be the result of the deposition of the heavier molecular fraction of the oil. Oil C and Oil D had lower viscosity than mineral base even at $100^{\circ} \mathrm{C}$.

2. Oil $\mathrm{C}$ possesses lower wear than any other base oil as observed from the wear analysis. The Oil $\mathrm{C}$ wear area was comparable to mineral oil with $0.25 \%$ of additives that demonstrate the potential of the renewable source as a base lubricant that may not require as many additives as mineral oils.

3. Functional groups of the $\mathrm{Oil} \mathrm{B}, \mathrm{C}$, and $\mathrm{D}$ mainly consisted of $\mathrm{C}=\mathrm{O}$ stretching functional group from oleic acid content, which helped to attract with the metal surface to form a film layer during boundary lubrication.

4. All the considered bio-derived oils have a lower COF as compared to mineral oil at the boundary regimes. The presence of oxygenates in the vegetable oil reacts with the surface and improves the lubricity of the oil.

5. The abrasive wear mechanism was observed from the optical microscope images that also included the debris from the surface. The clear abrasive grooves could be seen on the surface and Oil C had the lower wear volume, possibly due to the presence of higher oleic and lower PUFA content.

\section{Acknowledgment}

The author wishes to acknowledge Zeeland Farm Services, Inc, (Zeeland, MI), DowDuoPont (Wilmington, DE), The Lubrizol Corporation (Wickliffe, OH), and Petro-Canada Lubricants Inc. (Calgary, Canada) for their generous supply of the oils. The author would also like to thank United Soybean Board for funding this research. The author also wishes to acknowledge Dr. Rakish Shrestha, Dr. Swarna Saha, Dr. Rajdeep Shakya, and Sanjita Wasti for their help and guidance during the study. 
Vol. 06, No. 05; 2021

ISSN: $2456-8643$

\section{REFERENCES}

[1] R. de la Huz, M. Lastra, J. Junoy, C. Castellanos, J.M. Viéitez, Biological impacts of oil pollution and cleaning in the intertidal zone of exposed sandy beaches: Preliminary study of the "Prestige" oil spill, Estuar. Coast. Shelf Sci. 65 (2005) 19-29. https://doi.org/https://doi.org/10.1016/j.ecss.2005.03.024.

[2] A. Adhvaryu, S.Z. Erhan, Epoxidized soybean oil as a potential source of hightemperature lubricants, Ind. Crops Prod. 15 (2002) 247-254. https://doi.org/https://doi.org/10.1016/S0926-6690(01)00120-0.

[3] H. Nam, S. Wang, K.C. Sanjeev, M.W. Seo, S. Adhikari, R. Shakya, D. Lee, S.R. Shanmugam, Enriched hydrogen production over air and air-steam fluidized bed gasification in a bubbling fluidized bed reactor with $\mathrm{CaO}$ : Effects of biomass and bed material catalyst, Energy Convers. Manag. 225 (2020) 113408. https://doi.org/10.1016/J.ENCONMAN.2020.113408.

[4] K.C. Sanjeev, S. Adhikari, R.L. Jackson, N. Jain, Friction and wear properties of biomassderived oils via thermochemical conversion processes, Biomass and Bioenergy. 155 (2021) 106269. https://doi.org/10.1016/J.BIOMBIOE.2021.106269.

[5] R. Shakya, S. Adhikari, R. Mahadevan, S.R. Shanmugam, H. Nam, E.B. Hassan, T.A. Dempster, Influence of biochemical composition during hydrothermal liquefaction of algae on product yields and fuel properties, Bioresour. Technol. 243 (2017) 1112-1120. https://doi.org/10.1016/J.BIORTECH.2017.07.046.

[6] S. Thangalazhy-Gopakumar, S. Adhikari, H. Ravindran, R.B. Gupta, O. Fasina, M. Tu, S.D. Fernando, Physiochemical properties of bio-oil produced at various temperatures from pine wood using an auger reactor, Bioresour. Technol. 101 (2010) 8389-8395. https://doi.org/10.1016/j.biortech.2010.05.040.

[7] S. KC, P.D. Nezhadfar, C. Phillips, M.S. Kennedy, N. Shamsaei, R.L. Jackson, Tribological behavior of 17-4 PH stainless steel fabricated by traditional manufacturing and laser-based additive manufacturing methods, Wear. 440-441 (2019) 203100. https://doi.org/10.1016/j.wear.2019.203100.

[8] R. Jackson, J. Lei, Hydrodynamically Lubricated and Grooved Biomimetic Self-Adapting Surfaces, J. Funct. Biomater. 5 (2014) 78-98. https://doi.org/10.3390/jfb5020078.

[9] Y. Singh, A. Farooq, A. Raza, M.A. Mahmood, S. Jain, Sustainability of a non-edible vegetable oil based bio-lubricant for automotive applications: A review, Process Saf. Environ. Prot. 111 (2017) 701-713. https://doi.org/10.1016/j.psep.2017.08.041.

[10] H.A. Spikes, Boundary Lubrication and Boundary Films, in: D. Dowson, C.M. Taylor, T.H.C. Childs, M. Godet, G. Dalmaz (Eds.), Thin Film. Tribol., Elsevier, 1993: pp. 331346. https://doi.org/https://doi.org/10.1016/S0167-8922(08)70389-4.

[11] H. Hirani, Fundamentals of Engineering Tribology with Applications, 2016. https://doi.org/10.1017/cbo9781107479975.

[12] C.C. Ting, C.C. Chen, Viscosity and working efficiency analysis of soybean oil based biolubricants, Measurement. 44 (2011) 1337-1341. https://doi.org/10.1016/J.MEASUREMENT.2011.04.005.

[13] W. Castro, J.M. Perez, S.Z. Erhan, F. Caputo, A Study of the Oxidation and Wear 
Properties of Vegetable Oils : Soybean Oil Without Additives, (2006).

[14] A. Adhvaryu, S.Z. Erhan, J.M. Perez, Tribological studies of thermally and chemically modified vegetable oils for use as environmentally friendly lubricants, Wear. 257 (2004) 359-367. https://doi.org/10.1016/j.wear.2004.01.005.

[15] B.K. Sharma, J.M. Perez, S.Z. Erhan, Soybean oil-based lubricants: A search for synergistic antioxidants, Energy and Fuels. 21 (2007) 2408-2414. https://doi.org/10.1021/ef0605854.

[16] K. Lal, V. Carrick, Performance testing of lubricants based on high oleic vegetable oils, J. Synth. Lubr. 11 (1994) 189-206. https://doi.org/10.1002/jsl.3000110304.

[17] I. Minami, S. Mitsumune, Antiwear Properties of Phosphorous-Containing Compounds in Vegetable Oils, Tribol. Lett. 13 (2002) 95-101. https://doi.org/10.1023/A:1020152615786.

[18] K. Cheenkachorn, A Study of Wear Properties of Different Soybean Oils, Energy Procedia. 42 (2013) 633-639. https://doi.org/10.1016/j.egypro.2013.11.065.

[19] J.Z. Adamczewska, D. Wilson, Development of ecologically responsive lubricants, J. Synth. Lubr. 14 (1997) 129-142. https://doi.org/10.1002/jsl.3000140203.

[20] O.O. Fasina, H. Hallman, M. Craig-Schmidt, C. Clements, Predicting temperaturedependence viscosity of vegetable oils from fatty acid composition, JAOCS, J. Am. Oil Chem. Soc. 83 (2006) 899-903. https://doi.org/10.1007/s11746-006-5044-8.

[21] C.C. Ting, C.C. Chen, Viscosity and working efficiency analysis of soybean oil based biolubricants, Measurement, Vol 44, Issue 8, October 2011, Page 1337-1341

[22] N.J. Fox, G.W. Stachowiak, Vegetable oil-based lubricants-A review of oxidation, Tribol. Int. 40 (2007) 1035-1046. https://doi.org/10.1016/J.TRIBOINT.2006.10.001.

[23] R. Seemamahannop, K. Bilyeu, Y. He, S. Kapila, V. Tumiatti, M. Pompili, Assessment of oxidative stability and physical properties of high oleic natural esters, in: Proc. - IEEE Int. Conf. Dielectr. Liq., 2019. https://doi.org/10.1109/ICDL.2019.8796627.

[24] Anon, Lubricant additives, Ind. Lubr. Tribol. (1973). https://doi.org/10.1201/9780429466755-4.

[25] Y. Su, L. Gong, D. Chen, An investigation on tribological properties and lubrication mechanism of graphite nanoparticles as vegetable based oil additive, J. Nanomater. (2015). https://doi.org/10.1155/2015/276753.

[26] P.L. Menezes, S.P. Ingole, M. Nosonovsky, S. V. Kailas, M.R. Lovell, Tribology for scientists and engineers: From basics to advanced concepts, 2013. https://doi.org/10.1007/978-1-4614-1945-7.

[27] R.J. Chittenden, D. Dowson, J.F. Dunn, C.M. Taylor, THEORETICAL ANALYSIS OF THE ISOTHERMAL ELASTOHYDRODYNAMIC LUBRICATION OF CONCENTRATED CONTACTS. I. DIRECTION OF LUBRICANT ENTRAINMENT COINCIDENT WITH THE MAJOR AXIS OF THE HERTZIAN CONTACT ELLIPSE., Proc. R. Soc. London, Ser. A Math. Phys. Sci. 397 (1985). https://doi.org/10.1098/rspa.1985.0014.

[28] J.C.J. Bart, E. Gucciardi, S. Cavallaro, 2 - Principles of lubrication, in: J.C.J. Bart, E. Gucciardi, S.B.T.-B. Cavallaro (Eds.), Woodhead Publ. Ser. Energy, Woodhead Publishing, 2013: pp. 10-23. https://doi.org/https://doi.org/10.1533/9780857096326.10.

[29] M. Reyes, A. Neville, The effect of anti-wear additives, detergents and friction modifiers 
in boundary lubrication of traditional Fe-base materials, in: Tribol. Ser., 2003. https://doi.org/10.1016/s0167-8922(03)80119-0.

[30] M. Shahabuddin, H.H. Masjuki, M.A. Kalam, M.M.K. Bhuiya, H. Mehat, Comparative tribological investigation of bio-lubricant formulated from a non-edible oil source (Jatropha oil), Ind. Crops Prod. 47 (2013) 323-330.

https://doi.org/https://doi.org/10.1016/j.indcrop.2013.03.026.

\section{Appendix A}

\begin{tabular}{|l|l|l|l|}
\hline Sample & Trade Name & Composition & Supplier \\
\hline Oil A & $\begin{array}{l}\text { Conventional } \\
\text { Soybean oil }\end{array}$ & $23 \%$ oleic acid & Zeeland Farm Services Inc. (Zeeland, MI) \\
\hline Oil B & High Oleic Canola & $80 \%$ oleic acid & DowDuPont (Wilmington, DE) \\
\hline Oil C & Plenish & $75 \%$ oleic acid & DowDuPont (Wilmington, DE) \\
\hline Oil D & Vistive & $70 \%$ oleic acid & Zeeland Farm Services Inc. (Zeeland, MI) \\
\hline ISO 68 & Paraflex HT & Base oil & $\begin{array}{l}\text { Petro-Cananda Lubricants Inc. (Calgary, } \\
\text { Canada) }\end{array}$ \\
\hline Add & Additives & $\begin{array}{l}\text { Mixture of } \\
\text { chemicals }\end{array}$ & The Lubrizol Corporation (Wickliffe, OH) \\
\hline
\end{tabular}

\section{Appendix B}

Hersey Number $=\frac{\text { Dynamic viscosity } x \text { Speed } x \text { Radius }}{\text { Load }}$

\section{Appendix C}

Input parameters:

Radius of ball $=5 \mathrm{~mm}$

Elastic modulus of ball $=210 \mathrm{GPa}$

Poisson ratio of ball $=0.29$

Elastic Modulus of sample $=205 \mathrm{GPa}$

Poission ration of sample $=0.3$

Pressure viscosity coefficient $(1 / \mathrm{GPa})=0.1$ 
Mini speed $(\mathrm{m} / \mathrm{s})=0.0016$

$\operatorname{Max} \operatorname{speed}(\mathrm{m} / \mathrm{s})=0.67$

$\operatorname{Load}(\mathrm{N})=50$

Elastohydrodynamic lubrication was used to calculate the minimum film thickness and lambda ratio. Minimum film thickness is the minimum separation two surfaces to avoid direct contact. Chittenden et al. [24] studied the minimum film thickness and central film thickness with major axis of the Herztian contact ellipse which was used to compute the minimum film thickness.

The minimum film thickness is calculated as:

$H \min =3.64 \cdot G^{0.49} \cdot U^{0.68} \cdot W^{-0.073}\left(1-e^{-0.67\left(\frac{R_{y}}{R_{x}}\right)^{\frac{3}{3}}}\right)$

$\mathrm{G}, \mathrm{U}$, and $\mathrm{W}$ are dimensional less parameters and are calculated as:

$G=\propto_{p} E^{\mid} \ldots . .(\mathrm{b})$

$U=\frac{\eta \underline{u}}{\left.E\right|_{R_{x}}} \ldots \ldots . . .(\mathrm{c})$

$W=\frac{F}{\left.E\right|_{x} ^{2}} \ldots \ldots(\mathrm{d})$

where,

$$
\begin{aligned}
& \alpha_{p}=\text { Pressure viscosity coefficient } \\
& E^{\prime}=\text { Equivalence modulus of elasticity } \\
& \eta=\text { viscosity } \\
& u=\text { entering velocity of the fluid } \\
& F=\text { load } \\
& R=\text { radius of the contacting surfaces }
\end{aligned}
$$

For varying dynamic viscosity minimum film thickness was evaluated as shown in table B1 
Table B1: Minimum film thickness of each oil

\begin{tabular}{|c|c|c|c|c|c|}
\hline Sliding Speed & Oil A & Oil B & Oil C & Oil D & ISO 68 \\
\hline $\mathrm{m} / \mathrm{s}$ & $h_{\min }(\mathrm{nm})$ & $h_{\min }(n m)$ & $h_{\min }(n m)$ & $h_{\min }(\mathrm{nm})$ & $h_{\min }(\mathrm{nm})$ \\
\hline 0.0016 & 0.09 & 0.08 & 0.09 & 0.09 & 0.1 \\
\hline 0.00335 & 0.95 & 0.89 & 0.96 & 0.96 & 1.07 \\
\hline 0.0084 & 1.5 & 1.41 & 1.53 & 1.53 & 1.69 \\
\hline 0.0168 & 1.97 & 1.86 & 2.01 & 2.01 & 2.22 \\
\hline 0.0335 & 2.39 & 2.25 & 2.43 & 2.43 & 2.7 \\
\hline 0.084 & 2.78 & 2.62 & 2.83 & 2.83 & 3.13 \\
\hline 0.134 & 3.14 & 2.96 & 3.2 & 3.2 & 3.56 \\
\hline 0.167 & 3.49 & 3.29 & 3.55 & 3.55 & 3.94 \\
\hline 0.251 & 3.82 & 3.6 & 3.89 & 3.89 & 4.31 \\
\hline 0.335 & 4.14 & 3.9 & 4.21 & 4.21 & 4.67 \\
\hline 0.42 & 4.44 & 4.19 & 4.52 & 4.52 & 5.01 \\
\hline 0.502 & 4.74 & 4.47 & 4.83 & 4.83 & 5.35 \\
\hline 0.586 & 5.03 & 4.74 & 5.12 & 5.12 & 5.67 \\
\hline 0.67 & 5.31 & 5 & 5.41 & 5.41 & 5.99 \\
\hline
\end{tabular}

The lambda ratio is the minimum film thickness $\left(\mathrm{h}_{\min }\right)$ in relation to the RMS roughness of the contacting surface.

$\lambda=\frac{h \min }{\sqrt{R_{q 1}^{2}+R_{Q 2}^{2}}} \ldots . .(\mathrm{b})$

where, $\mathrm{h}_{\min }=$ minimum film thickness

$$
R_{\mathrm{q}}=\mathrm{RMS} \text { roughness of two contacting surfaces }
$$

From minimum film thickness, lambda ratio was evaluated by dividing by the average sample roughness as shown in table B2 
Table B2: Lambda ratio of each oil

\begin{tabular}{|c|l|l|l|l|l|}
\hline $\begin{array}{l}\text { Sliding } \\
\text { Speed }(\mathbf{m} / \mathbf{s})\end{array}$ & Oil A & Oil B & Oil C & Oil D & ISO 68 \\
\hline 0.0016 & 0.000622 & 0.000553 & 0.000622 & 0.000622 & 0.000691 \\
\hline 0.00335 & 0.006565 & 0.00615 & 0.006634 & 0.006634 & 0.007394 \\
\hline 0.0084 & 0.010365 & 0.009743 & 0.010573 & 0.010573 & 0.011678 \\
\hline 0.0168 & 0.013613 & 0.012853 & 0.013889 & 0.013889 & 0.015341 \\
\hline 0.0335 & 0.016515 & 0.015548 & 0.016792 & 0.016792 & 0.018657 \\
\hline 0.084 & 0.01921 & 0.018105 & 0.019556 & 0.019556 & 0.021629 \\
\hline 0.134 & 0.021698 & 0.020454 & 0.022112 & 0.022112 & 0.0246 \\
\hline 0.167 & 0.024116 & 0.022734 & 0.024531 & 0.024531 & 0.027226 \\
\hline 0.251 & 0.026397 & 0.024876 & 0.02688 & 0.02688 & 0.029783 \\
\hline 0.335 & 0.028608 & 0.02695 & 0.029092 & 0.029092 & 0.03227 \\
\hline 0.42 & 0.030681 & 0.028953 & 0.031234 & 0.031234 & 0.03462 \\
\hline 0.502 & 0.032754 & 0.030888 & 0.033376 & 0.033376 & 0.036969 \\
\hline 0.586 & 0.034758 & 0.032754 & 0.03538 & 0.03538 & 0.03918 \\
\hline 0.67 & 0.036693 & 0.034551 & 0.037384 & 0.037384 & 0.041392 \\
\hline
\end{tabular}

